\title{
Usage of Gamification Theory for Increase Motivation of Employees
}

\author{
Kamasheva A.V.a \\ Valeev E.R. ${ }^{b}$ \\ Yagudin R.Kh.c \\ Maksimova K.R.d \\ a bd Kazan Federal University, Institute of Management, Economics and Finance, Kazan, 420008, Russia \\ Email: hulia_k@mail.ru \\ ${ }^{c}$ Republican Clinical Hospital, 420064, Kazan, Orenburg tract, 138, Russia
}

Doi:10.5901/mjss.2015.v6n1s3p77

\section{Abstract}

Games have amazing ability to hold people's attention for a long time, build relationship, win recognition and develop creativity. Games can be considered as a sample of motivation and job involvment, so now we are trying to apply these techniques into the labor process. In the following article gamification term is given and history of gamification theory is analyzed. Besides problems of application of gamification method in sector of national economy are examined. Also analysis of the possibilities of implementation this theory to the Russian reality is presented.

Keywords: gamification, employment, wage, payment, motivation

\section{Introduction}

Networks of different games widely spread in modern world. Professionals more often use game form for teaching children and adults. Organizations use different game forms for increase efficiency and productivity of employees. "Gamification" term was invented by British computer programmer Nick Pelling in 2002, but became widely used only in 2010.

Gamification is usage of game thinking and game mechanics in non-game context to engage users in solving problems. In other words, it is designed system that creates context where person willingly and effectively achieves goal. For decades game is considered as sample of motivation and involvement and nowadays we try to learn this technology from games.

\section{Theory}

During game people spend time for something that doesn't improve neither their lives nor others (expect game makers). But if we could use all energy and interest of people that appears during game and transfer it to important and effective solutions of problems, results would be positive for all. In this case employer would have motivated and productive workers, and therefore better results and more profits; and employee, enjoying game process, increases incomes and climbs career ladder. And if usually person simply wastes time playing computer games, here the more time he spends playing "business-game" the more successful he becomes.

Gamification methods in personnel administration are used for recruitment, organizational problems solving, stimulation employees' initiative and improvement of the corporate culture and preservation of valuable employees (pic.1). Modern generation of workers is more focused on divers use of their knowledge, skills, creativity and is looking for freedom, independence and realization of personal potential in profession, that makes gamification (a new trend in management) as relevant as ever. 


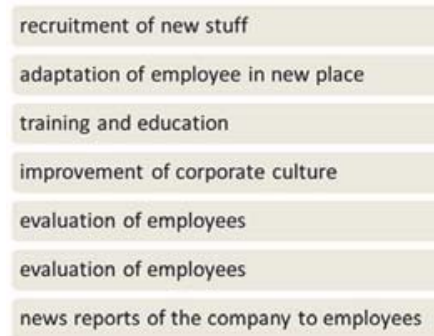

Pic. 1. Gamification methods in personnel administration

As a reward respect of management and stuff or financial rewards can be considered. There are several other ways of motivation such as bonuses, career growth or obtaining the right to purchase shares of the company at a discounted price[3]. Non-financial motivation includes acquisition of new skills, admission to more important work, comprehension of importance to the company and, finally, pleasure of work done.

Wage rate cannot directly depend on game results since gamification is based on voluntary participation. Otherwise according to law it can be considered as discrimination against other employees on unverifiable criterion and as hidden additional duties that official duties do not consist of. In the structure of wages gamification cannot influence on guaranteed part, but assumes application of bonuses in addition to the basic system of bonuses.

In the system of gamification there are 3 main groups of game mechanics:

1) Olympiad: competitive mechanics,

2) Win-Win: mechanics without winners and losers,

3) Aesthetics: mechanics focused on visualization

Table 1. Basic game mechanics

\begin{tabular}{|c|c|c|c|}
\hline $\begin{array}{c}\text { Group of mechanics } \\
\text { Tasks: }\end{array}$ & Olympiad & $\begin{array}{l}\text { Win- } \\
\text { Win }\end{array}$ & Aesthetics \\
\hline To increase overall level of productivity & + & & \\
\hline To identify leaders & + & & \\
\hline $\begin{array}{l}\text { To identify vector of development of particular employee and the whole team and promote } \\
\text { their development in this direction }\end{array}$ & & + & + \\
\hline To provide all employees immediate feedback on the results of activities & & + & \\
\hline To increase the visibility of the results of each employee & + & + & + \\
\hline To improve quality of communication in team & & + & \\
\hline To decrease the amount of conflicts & & + & \\
\hline To unite employees with common idea, to involve in team work & + & + & \\
\hline To inculcate values of the company to employees, to form an understanding of HR-brand & + & + & + \\
\hline
\end{tabular}

With the implementation of gamification techniques in the field of personnel management the question of the legal component of the process raises. Relations arising in gamification fall under the requirements of the civil law. Gamification is not directly related to the financial benefits, but there is an indirect link.

Professor Werbach suggested structure of gamification elements (pic.2), where the first basic level presents gamification components, the second - mechanics and the third - game dynamics[11].

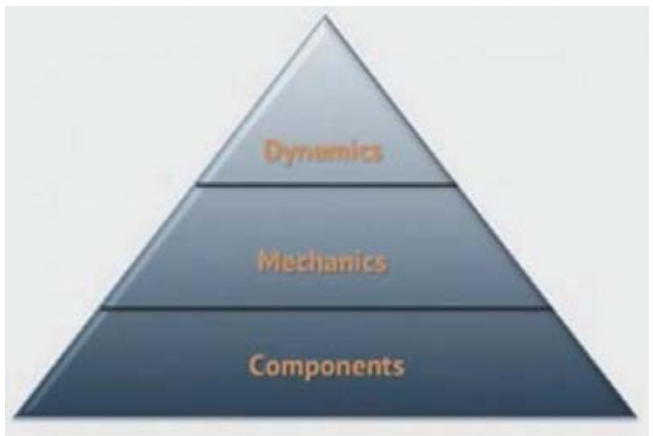

Pic. 2. Elements of gamification 
Components of gamification are appearance like user avatar, levels of game, process-bars, badges that can be given for achievements, leader-boards, quests, virtual goods. The mechanical elements of the game are tools that can help to figure out how to move the action forward and get the players into the game such as rewards, resource acquisition, feedback, competition and cooperation[7]. Dynamics consists of emotions, relationships between players and progression of player. Important factor is that gamification of business processes including personnel management should encourage people to participate only on voluntary basis.

\section{Result}

Among the most well-known companies that use theory of gamification is AOL, Microsoft, eBay, Cisco, IBM, L'Oreal, Coca-Cola, Disney, Dell, Nike, NBC, Nissan, HP, Pepsi, Warner Brothers, Viacom, Samsung, Comcast, RecycleBank, Volkswagen, Facebook, Siemens, American Express, EMC. In Russia gamification use such companies as Uralian bank of reconstruction and development, Alfa-bank, Rosatom, M-video, Bank Vostochnyj-express, Altoros, Hlebprom and others.

A lot of minuses of this system can be found: improper of fake motivation, irrelevant awards and inadequate mechanisms. Each of these drawbacks does not allow achieving desired level of motivation and in some cases can lead to the opposite effect[1]. Low quality game systems do not engage audience as it is something more than distribution of badges and tabulation of leaders. Badges and leader table are undoubtedly among basic tactics of gamification, yet without specific business goals one cannot do.

Gamification system is very complicated in development; there is no flexible product that could work in every organization or at least at all departments of one company. It often happens that gamification is incompatible with particular corporate culture. When there is no holistic vision, it is impossible to incorporate new mechanisms in HR and so gamification does not bring significant results.

It is said that gamification can work well only with young employees as the term "game" is closer to young people. However, new popular gamification theory was widely spread and actively practiced on the territory of the Soviet Union and Eastern countries, as socialistic competitions of employees (that were popular those days) meet the requirements of gamification theory[5]. Remembering old methods of increasing motivation older generation is tolerant to implementation of principles in new forms.

Socialist competitions are competitions between employees, teams, departments and enterprises in order to develop labour productivity, cut production costs and strengthening of work discipline[8]. The aim of socialist competition was to show creative initiative, improve product quality and increase the rate of scientific and technological progress and efficiency.

First contract about socialist competition was published in 1929 in newspaper "Truth". The article "Contract about socialist competition of fettlers from pipe department of "Krasniy viborjets" enterprise" laid the foundation of numerous socialist competitions in the USSR.[2] Competitions of employees developed due to shock work and Stakhanovism. The aim of this process was to have high performance rates, that are achieved by individual workers, who were not the best in their field, so that it created conditions for a revision of old standards of development and improvement of material and technical base.

At the same time at the basis of this movement laid moral motives such as sense of duty and moral incentive. Contentiousness and competition (that were a part of the contest) were supposed to increase number of success, to demonstrate abilities and personal fulfillment. The goal of such competition was the product and not the profit, that is was it was considered as the most effective factor in development of society.

\section{Conclusion}

Let us analyze socialist competitions in terms of modern theory of gamification. Important components for victory in socialist competitions were merit badges such as "Winner of socialist competition". Winners had both material and moral rewards. Material rewards were money, goods or benefits that are typical for the socialist system, such as tickets to resorts, permission to travel abroad, right to receive housing or car out of the main line[6]. Moral rewards were diplomas, badges, portraits of winners posted on the board of honour. Labor collectives were awarded with challenge winner banner.

Thus gamification is a tool that can bring the relationship between employer and employee to a new level, which goes beyond frames of wages and labor contract and is based on feedback, recognition, status and self-fulfillment.

Creation of a game system is individual for every company and there can be no ready-made solutions, as the aim 
of game mechanics is strengthening weak sides of company among which could be small operation speed, weak customer orientation, low employee loyalty, absence of effective internal communications, increased level of conflicts.

\section{References}

Astor, A., Akhtar, T., Matallana, M.A., Muthuswamy, V., Olowu, F., Tallo, V., Lie, R., 2005. Physician migration: views from professionals in Colombia, Nigeria, India, Pakistan and the Philippines. // Social Science \& Medicine 61, 2492-2500

Fakhrutdinova, E., Fakhrutdinova, A.,Severyanov, O., Valeev, E. The transformation of educational approaches at the time of social and economical changes // World Applied Sciences Journal 2013. 27 (13), pp. 15-19

Fakhrutdinova, E., Kolesnikova, J., Yurieva, O.,Kamasheva, A. The commercialization of intangible assets in the information society /I World Applied Sciences Journal2013 27 (13), pp. 82-86

Griffiths, M., Wardle, J., Orford, J., Sproston, K., \& Erens, B. Socio-demographic correlates of internet gambling: // Findings from the 2007 British Gambling Prevalence Survey. CyberPsychology and Behavior, 12, 199-202.

Hamari, J. Transforming homo economicus into homo ludens: A field experiment on gamification in a utilitarian peer-to-peer trading service // Electronic Commerce Research and Applications 2013

Hamari, J.,Koivisto, J.,Sarsa, H. Does gamification work? - A literature review of empirical studies on gamification // Proceedings of the Annual Hawaii International Conference on System Sciences 2014 p

Huotari, K.,Hamari, J. Defining gamification - A service marketing perspective // Proceedings of the 16th International Academic MindTrek Conference 2012: "Envisioning Future Media Environments", MindTrek 2012

Kamasheva, A, Kolesnikova, J , Karasik, E, Salyakhov E. Discrimination and Inequality in the Labor Market // Procedia Economics and Finance Volume 5, 2013, Pages 386-392 International Conference On Applied Economics (ICOAE) 2013

Lehdonvirta, V. Hamari, J. Game design as marketing: How game mechanics create demand for virtual goods International Journal of Business Science and Applied Management 2010

Melnik A.N., Mustafina O.N. The Organization of Russian Power Market in Modern Conditions // Middle-East Journal of Scientific Research 13. - 2013. - P. 91-94.

Werbach, K (Re)defining gamification: // A process approach Lecture Notes in Computer Science (including subseries Lecture Notes in Artificial Intelligence and Lecture Notes in Bioinformatics) 2014.

Kramin, M. V., Safiullin, L. N., Kramin, T. V., \& Timiryasova, A. V. (2014). Drivers of economic growth and investment attractiveness of Russian regions. Life Science Journal, 11(6s).

Kramin, T. V., Ismagilova, G. N., \& Kramin, M. V. (2014). Assessment of Effect of Large Investment Projects on Development of Investment Potential of Regions of Russia as Exemplified by Universiade 2013 in Kazan1. Mediterranean Journal of Social Sciences, 5(18), 255.

Kramin, T. V., Safiullin, L. N., \& Timiryasova, A. V. (2014). Defining Priorities of Management of Investment Attractiveness of the Region and their Consideration in the Framework of Implementing Large Sports Events1. Mediterranean Journal of Social Sciences, 5(18), 275. 